\title{
Routine use of counter-immunoelectrophoresis test for detecting antibody to hepatitis B virus core antigen
}

\author{
R. FREEMAN AND M. H. HAMBLING \\ From the Virology Department, Public Health Laboratory, Bridle Path, York Road, Leeds LS15 7TR, UK
}

SUMMARY Tests by counter-immunoelectrophoresis for antibody to hepatitis B core antigen (anti-HBc) were introduced into a routine testing programme for evidence of hepatitis B virus inféction. Samples tested for anti-HBc were selected on the basis of the results of tests for $\mathrm{HBsAg}$ and clinical details. The sensitivity and specificity of the test were assessed and correlations made with the presence of HBsAg.

The presence of anti-HBc was very useful in the interpretation of a doubtful positive result for HBsAg in the haemagglutination test. With very few exceptions the serum samples positive for HBsAg by routine tests also contained anti-HBc.

It is concluded that the test is valuable and merits introduction into routine testing programmes.

It has been suggested (Cohen and Cossart, 1977) that the testing of serum samples for antibody to hepatitis B core antigen (anti-HBc) by counter-immunoelectrophoresis $^{1}$ (CIEP) would be a useful addition to the battery of tests used to detect past and present infection with hepatitis B virus. Recently, limited routine tests for anti-HBc have been used in this laboratory, and these results are now described.

\section{Material and methods}

During routine testing of sera from patients for evidence of hepatitis $B$ virus infection during the period March to October 1977, 255 of the samples were also tested for anti-HBc and grouped as follows:

Group A consisted of 74 serum samples in which the results of turkey erythrocyte haemagglutination tests (Hepatest) for hepatitis B surface antigen (HBsAg) were not clearly positive or negative, and in which HBsAg was not detected by CIEP or immunoelectron microscopy (IEM). In subsequent tests by radioimmunoassay (RIA) six of these 74

\footnotetext{
'The term 'counter-immunoelectrophoresis' is used in accordance with the nomenclature of WHO Technical Report Series No. 602 and in preference to the sometimes used term 'immunoelectro-osmophoresis'
}

Received for publication 13 February 1978 samples were found to be positive for $\mathrm{HBsAg}$ (Table 1).

Table 1 Results of tests for anti-HBc on 255 serum samples divided into groups



Group B consisted of 82 samples positive for HBsAg by one or more of the following tests: CIEP, IEM, turkey erythrocyte haemagglutination, or RIA.

Group C consisted of 30 serum samples from patients with a documented history of hepatitis B 
infection, in whom routine tests for $\mathrm{HBsAg}$ had become negative. In this group, 10 samples contained anti-HBs but it was not detected in the remaining 20 , although these latter samples were free of $\mathrm{HBsAg}$ by RIA tests.

Group D consisted of sera from 63 blood donors whose donations may have been associated with post-transfusion hepatitis; these are referred to as 'J' file donors. All tests for $\mathrm{HBsAg}$, including RIA, on these donations were negative.

Group E consisted of six sera from babies born to five women who were either chronic carriers of HBsAg or had had an acute episode of hepatitis B during the pregnancy. These mothers, whether or not their serum contained $\mathrm{HBsAg}$, were shown to possess anti-HBc at the end of the pregnancy.

\section{TESTS FOR HBSAg}

HBsAg was detected by passive haemagglutination of treated turkey erythrocytes (Hepatest, Wellcome Reagents), CIEP (Milne and Barr, 1971), and IEM. Sera found positive at a titre of $1 / 8$ in the haemagglutination test were titrated in serial eightfold dilutions to a dilution of $1 / 4096$. Some specimens failed to give a definite positive or negative result in the haemagglutination test in that haemagglutination of both test and control turkey erythrocyte suspensions occurred. Such sera were retested after absorption with control cells. In most instances this procedure was successful but any specimen requiring absorption, whether successful or not, was considered to give an 'inconclusive' result unless the presence of HBsAg was established by CIEP or IEM.

\section{TESTS FOR ANTI-HBS}

Anti-HBs was detected by passive haemagglutination inhibition (PHAI) using the Hepatest reagents. The virus dose consisted of four haemagglutinating units of $\mathrm{HBsAg}$ determined by previous titration, and sera were tested at dilutions of $1 / 4$ to $1 / 128$.

\section{TESTS FOR ANTI-HBC}

Anti-HBc was detected by CIEP using a technique similar to that for the detection of HBsAg; however, in this test the patient's serum is the presumed source of antibody so it was placed in the anodal $(+)$ well, and a standard preparation of hepatitis $B$ core antigen $(\mathrm{HBcAg})$ was placed in the cathodal well. It is important to emphasise that the CIEP technique used was of the continuous type since preliminary testing had shown that discontinuous CIEP gave inferior results. $\mathrm{HBcAg}$ was used at an optimal dilution previously determined by a titration against a serum known to contain anti-HBc; the method of preparation of this antigen was as described by Cohen and Cossart (1977).

\section{Results}

The results of tests for anti-HBc on 255 serum samples are shown in Table 1 . HBsAg was present in 88 samples, and 87 of these also contained anti-HBc. The single $\mathrm{HBsAg}$ positive/anti-HBc negative patient was a blood donor known to have been free of HBsAg six months previously; a later sample of serum has been shown to contain anti-HBc, and the donor has developed hepatitis. There was one patient in group $A$ who was $\mathrm{HBsAg}$ negative/anti-HBc positive; her brother was also found to be HBsAg negative/anti-HBc positive, and a past history of hepatitis was obtained from both.

Serum samples containing HBsAg from 82 patients were titrated using the Hepatest method and were also tested for HBsAg by IEM and CIEP. Anti-HBc was present in 81 of these samples and seemed to be unrelated to the HBsAg turkey erythrocyte haemagglutination titre (Table 2). Anti$\mathrm{HBc}$ was easily detected in the serum of two patients who were positive for HBsAg by the RIA test only. The single patient who was positive for HBsAg but lacked anti-HBc was the blood donor, previously mentioned, who subsequently developed hepatitis. In this group, two specimens with high haemagglutination titres $(\geqslant 1 / 4096)$ were originally negative for HBsAg by CIEP; when re-tested at a dilution of $1 / 10$ both showed a positive result.

The presence of anti-HBs was correlated with the presence of anti-HBc, and Table 3 shows that anti$\mathrm{HBc}$ was present only in patients with anti-HBs titres of $\geqslant 1 / 16$ by the PHAI test. Three patients with

Table 2 Correlation of presence of $\mathrm{HBs} A \mathrm{~g}$ by different tests with the presence of anti-HBc in 82 serum samples

\begin{tabular}{|c|c|c|c|c|c|c|c|c|}
\hline \multirow[t]{2}{*}{ No. in group } & \multicolumn{4}{|c|}{ Hepatest positive (reciprocal of haemagglutination titre) } & \multirow{2}{*}{$\begin{array}{l}\text { CIEP } \\
\text { positive }\end{array}$} & \multirow{2}{*}{$\begin{array}{l}\text { IEM } \\
\text { positive }\end{array}$} & \multicolumn{2}{|c|}{$A n t i-H B c$} \\
\hline & $\begin{array}{l}\geqslant 8- \\
<64\end{array}$ & $\begin{array}{l}\geqslant 64- \\
<512\end{array}$ & $\begin{array}{l}\geqslant 512- \\
<4096\end{array}$ & $\geqslant 4096$ & & & Present & $\begin{array}{l}\text { Not } \\
\text { detected }\end{array}$ \\
\hline $\begin{array}{l}5 \\
8 \\
47 \\
20 \\
2 \text { Positive by }\end{array}$ & $\frac{5}{-}$ & $\begin{array}{l}\overline{8} \\
- \\
-\end{array}$ & $\begin{array}{l}- \\
\overline{47} \\
-\end{array}$ & $\frac{-}{20}$ & $\begin{array}{r}0 \\
4 \\
47 \\
20\end{array}$ & $\begin{array}{r}3 \\
8 \\
47 \\
20\end{array}$ & $\begin{array}{r}5 \\
8 \\
46 \\
20 \\
2\end{array}$ & $\begin{array}{l}0 \\
0 \\
1 \\
0 \\
0\end{array}$ \\
\hline
\end{tabular}


Table 3 Relationship of presence of anti-HBc to (a) titre of anti-HBs or (b) time elapsed since attack of hepatitis $B$ virus infection

(a) Anti-HBs present

\begin{tabular}{llll}
$\begin{array}{l}\text { Anti-HBs titre by passive } \\
\text { haemagglutination inhibition }\end{array}$ & $\begin{array}{l}\text { No. of } \\
\text { samples }\end{array}$ & Anti-HBc \\
\cline { 3 - 4 } & & Present & $\begin{array}{l}\text { Not } \\
\text { detected }\end{array}$ \\
\hline $1 / 4$ & 2 & 0 & 2 \\
$1 / 8$ & 1 & 0 & 1 \\
$1 / 16$ & 4 & 4 & 0 \\
$1 / 32$ & 2 & 2 & 0 \\
$\geqslant 1 / 64$ & 1 & 1 & 0 \\
\hline
\end{tabular}

(b) Anti-HBs not detected at serum dilution of $1 / 4$

\begin{tabular}{llll}
$\begin{array}{l}\text { Months since acute } \\
\text { hepatitis } B \\
\text { virus infection }\end{array}$ & $\begin{array}{l}\text { No. of } \\
\text { samples }\end{array}$ & Anti-HBc & \\
\cline { 2 - 4 } & & Present & $\begin{array}{l}\text { Not } \\
\text { detected }\end{array}$ \\
\hline $1-6$ & 15 & 15 & 0 \\
$7-12$ & 2 & 2 & 0 \\
$13-36$ & 4 & 4 & 0 \\
$>36$ & 4 & 4 & 0 \\
\hline $38,50,51$, and 85) & 4 & 4 & 0 \\
\hline
\end{tabular}

anti-HBs titres of $<1 / 16$ had no anti-HBc in their sera. In 20 patients a definite past history of hepatitis accompanied by HBsAg in the serum was obtained, but anti-HBs was not detected in a $1 / 4$ serum dilution of samples collected at varying times after the acute episode. However, all 20 samples contained anti-HBc, even those in which the acute attack had occurred more than three years previously.

Serum was obtained from five babies born to women possessing anti-HBc in pregnancy, and Table 4 shows that anti-HBc was detectable for at least three months after birth. One child, in whom samples were obtained at 2 months and 8 months, was positive for anti-HBc at 2 months, but in the 8month sample anti-HBc could no longer be detected.

Table 4 Results of tests for anti-HBc on samples from babies born to women possessing anti-HBc in late pregnancy

\begin{tabular}{ll}
\hline Age of child & Anti-HBc \\
\hline 1 day & Present \\
4 days & Present \\
6 days & Present \\
2 months* & Present \\
3 months & Present \\
\hline months* & Not detected \\
\hline
\end{tabular}

Discussion

A satisfactory routine test for anti-HBc should be sensitive, specific, and technically acceptable. CIEP has been used by more than one group of workers to detect anti-HBc (Budkowska et al., 1974; Cohen and Cossart, 1977), and initial reports have been encouraging. While more sensitive methods, for instance, immune-adherence-haemagglutination (Tsuda et al., 1975), radioimmunoprecipitation (Moritsugu et al., 1975), and solid phase radioimmunoassay (Purcell et al., 1974), have been developed to detect anti-HBc, CIEP offers a simple and practical technique for routine work, provided the results are useful in the diagnosis or prognosis of hepatitis $B$ virus infection. At present the only serious limitation of CIEP for detecting anti-HBc is that suitable antigen is in short supply. Cohen and Cossart (1977), using CIEP, showed that in 59 cases of acute hepatitis B, anti-HBc was invariably present as well as HBsAg. Similarly, they found that all 20 samples from patients suffering from $\mathrm{HBsAg}$ positive chronic hepatitis contained anti-HBc. Their study did not include any asymptomatic carriers of HBsAg, whereas this series includes 42 specimens from such patients (Table 1). The results presented here confirm and extend those of Cohen and Cossart, and show that if a serum sample contains HBsAg, whether the sample is from a patient suffering from acute hepatitis or from an asymptomatic chronic carrier of $\mathrm{HBs} \mathrm{Ag}$, anti-HBc is almost always also present. Two exceptions to this statement may be noted. First, one of the patients listed in Table 1 (group B), and again in Table 2, did not have anti$\mathrm{HBc}$ in his serum although the sample contained very large amounts of HBsAg. This patient appears to have been tested originally in the incubation period of hepatitis $B$ virus infection, and the resuliant discrepancy (HBsAg+/anti-HBc-) is that described by Hoofnagle et al. (1975) as typical of this stage of the disease. A repeat sample taken after an interval of two weeks was shown to contain anti$\mathrm{HBc}$ as well as confirming the presence of HBsAg. Coincident with this second sample the patient developed hepatitis. The second situation in which anti-HBc may be absent despite the presence of HBsAg is in the severely immunosuppressed patient (Cohen and Cossart, 1977). Our series contains no such patient, but the possibility of this finding must always be remembered.

As shown in Table 2, the test for anti-HBc is just as reliably positive in the presence of very small or very large amounts of HBsAg. It should be noted that the CIEP test for HBsAg can occasionally be negative using neat serum when the amount of HBsAg is very large, although re-testing at a serum dilution of $1 / 10$ produces a satisfactory positive result. In our experience, this problem has not occurred with CIEP for anti-HBc, and in such sera 
the positive CIEP test for anti-HBc has confirmed the positive haemagglutination test result and led to the challenging of the negative result for $\mathrm{HBs} \mathrm{Ag}$ by CIEP.

It appears that CIEP for anti-HBc is a sensitive technique, which may be used for the confirmation of the presence of HBsAg given the provisos mentioned earlier. The absence of anti-HBc in a sample thought to contain HBsAg should lead to reexamination of all the findings.

Cohen and Cossart (1977) showed that anti-HBc could be found in the absence of HBsAg but that when this occurred anti-HBs was often also present, indicating past infection with hepatitis $B$ virus.Our findings confirm that in the few patients found during routine testing to possess anti-HBs, anti-HBc may also be present (Table 3a), and also show that anti-HBs is not necessarily accompanied by anti-HBc. Since anti-HBs is thought to decline in titre with the passage of time, and to persist longer than anti-HBc (Hoofnagle et al., 1975), it would be logical to expect anti-HBc to be associated with high-titre antiHBs more often than low-titre anti-HBs. This expectation is supported by the results in Table $3 \mathrm{a}$, which show that sera with high titres of anti-HBs also contain anti-HBc, whereas sera with low titres of anti-HBs have no detectable anti-HBc. This series also contains 20 samples collected from patients with a documented history of hepatitis B virus infection confirmed by the detection of HBsAg at the time, but in whom anti-HBs was not detected; the results of tests for anti-HBc on these specimens are shown in Table 3b. Anti-HBc was detected in all cases-in four samples more than three years after the acute attack. As 10 of the samples tested were obtained within six months of the acute illness antiHBs may still appear. Our test for the detection of anti-HBs (PHAI) is not as sensitive as the RIA method used by Cohen and Cossart, and some of the sera listed in Table $3 \mathrm{~b}$ may coniain anti-HBs at a low titre ( $<1 / 4$ by PHAI). These findings are difficult to interpret without a more sensitive test for anti-HBs but it seems that anti-HBc is a better indicator of fairly recent hepatitis $B$ infection than anti-HBs.

Cohen and Cossart also found that certain patients, usually those with $\mathrm{HBs} A g$ negative acute hepatitis, produced antibodies which reacted with the HBcAg preparation in CIEP tests but which they showed by other methods to be non-specific. In some cases a reaction could also be obtained with a 'normal' liver extract. Group A (Table 1) includes sera from 17 patients suffering from acute hepatitis. These 17 samples were negative for HBsAg by RIA, and in 15 anti-HBc was not detected. However, in the remaining two samples a precipitin line appeared in the gel, which was different in appearance, size. and situation from the type of line we associate with anti-HBc. We were unable to follow the procedure adopted by Cohen and Cossart (1977) whereby the gel line was excised and shown by electron microscopy to contain aggregated $\mathrm{HBcAg}$ particles in truly positive reactions, but in the two cases mentioned above the reaction was so different from the line usually found that no confusion was produced. No non-specific reactions to the core antigen were seen in the 63 samples from blood donors whose donations may have been associated with posttransfusion hepatitis; all 63 samples were negative for HBsAg by RIA and for anti-HBc by CIEP. The CIEP test for anti-HBc appears to be specific and useful for diagnostic purposes, provided an accurate medical history of the patient is available.

The technique for detecting anti-HBc by CIEP is familiar to many laboratories, especially those carrying out tests for HBsAg. Moreover, the method is rapid and economical and can be used to detect both HBsAg and anti-HBc. Serum samples giving inconclusive results in haemagglutination tests for HBsAg (group A, Table 1) cause a problem in laboratories lacking facilities for RIA. One possible solution to this situation is the recent introduction of enzyme-linked immunosorbent assay (ELISA) tests, which are stated to have a sensitivity for HBsAg approaching that of RIA (Wolters et al., 1976). However, ELISA tests take several hours to perform and are relatively expensive, whereas CIEP for anti-HBc is quick and economical, and the results on 74 sera in group A (Table 1) show that failure to detect anti$\mathrm{HBc}$ helped to confirm the absence of HBsAg.

Anti-HBc tests were positive on sera from the five infants (Table 4) born to mothers whose sera in late pregnancy contained anti-HBc; these mothers were either chronic HBsAg carriers or had suffered from hepatitis B infection in the pregnancy. It seems likely that anti-HBc crosses into the fetal circulation as a maternal antibody and slowly disappears; in a 2month-old infant the positive anti-HBc test had become negative six months later.

The results of this small series of CIEP tests for anti-HBc indicate that the test is sensitive, specific, and easy to carry out as a routine procedure. It is a useful addition to other tests in the assessment of past and present infection with hepatitis B virus. However, it should be emphasised that the results of tests for anti-HBc cannot be inierpreted without clinical information and the results of HBsAg tests.

We thank Dr Elizabeth H. Boxall, of the Regional Virus Laboratory, East Birmingham Hospital, for the results of radioimmunoassay tests for $\mathrm{HBsAg}$, and Dr C. M. Patricia Bradstreet, Standards Laboratory, Central Public Health Laboratory, Colindale 
Avenue, London, for the provision of hepatitis B core antigen.

\section{References}

Budkowska, K., Walicka, B., Domaniewska, G. A., and Brzosko, W. J. (1974). Immunoelectro-osmophoresis for detection of antibody to hepatitis B core antigen (Letter). New England Journal of Medicine, 290, 14891940.

Cohen, B. J., and Cossart, Y. E. (1977). Application of a screening test for antibody to hepatitis B core antigen. Journal of Clinical Pathology, 30, 709-713.

Hoofnagle, J. H., Gerety, R. J., and Barker, L. F. (1975). Hepatitis B core antigen and antibody. Developments in Biological Standardization, 30, 175-185.

Milne, G. R., and Barr, A. (1971). A rapid method for testing blood for hepatitis associated antigen and antibody using counter-current electrophoresis (immunoelectro-osmophoresis) in agarose gel. Technical Bulletin No. 1, Sterilin Products Ltd.
Moritsugu, Y., Gold, J. W. M., Wagner, J., Dodd, R. Y. and Purcell, R. H. (1975). Hepatitis B core antigen: detection of antibody by radioimmunoprecipitation. Journal of Immunology, 114, 1792-1798.

Purcell, R. H., Almeida, J. D., Gerin, J. L., and Holland, P. V. (1974). Radioimmunoassay for the detection of the core of the Dane particle and antibody to it. Intervirology, 2, 231.

Tsuda, F., Takahashi, T., Takahashi, K., Miyakawa, Y., and Mayumi, M. (1975). Determination of antibody to hepatitis B core antigen by means of immune adherence hemagglutination. Journal of Immunology, 115, 834838.

Wolters, G., Kuijpers, L., Kačaki, J., and Schuurs, A. (1976). Solid phase enzyme-immunoassay for detection of hepatitis B surface antigen. Journal of Clinical Pathology, 29, 873-879.

Requests for reprints to: Dr R. Freeman, Newcastle General Hospital, Westgate Road, Newcastle-upon-Tyne. 